Cadernos de Filosofia Alemã 2, P. 61-75, 1997

\title{
Von dem ersten Grunde des Unterschiedes der Gegenden im Raume
}

\author{
Sobre o primeiro fundamento \\ da distinção de direções no espaço
}

\author{
Immanuel Kant
}

\begin{abstract}
$\mathrm{O}$ artigo aqui traduzido, publicado pela primeira vez em 1768 no Wochentliche Königsbergsche Frag- und Anzeigungsnachrichten (nos 6-8), é geralmente conhecido por sua discussão das chamadas contrapartidas incongruentes. Dos textos de Kant, é o que trata mais detalhadamente do tema. A primeira referência ao assunto, porém, aparece em 1763 na Metaphysik Herder (Ak. vol. 28, p. 15), tendo o assunto estado implicitamente presente nos demais escritos de Kant da década de 1760. As duas referências mais importantes ao tema posteriores ao artigo de 1768 encontram-se na Dissertação de 1770 ( 115 C) e nos Prolegômenos (§ 13).

A questão na qual o artigo se detém é a de se o espaço é anterior às coisas (cf. Reflex. 4515). Kant contrapõe-se à concepção leibniziana do espaço, que ele próprio havia defendido em escritos anteriores, mostrando que "a concepção de muitos filósofos recentes, principalmente alemães, segundo a qual o espaço consistiria apenas nas relações externas das partes da matéria situadas umas ao lado das outras" (Ak. 383) é insuficiente para dar conta do fato de que a orientação de um corpo (a direção para a qual está voltado) é uma característica espacial. Sem levar em conta esta característica, não seríamos capazes de fazer coisas tão usuais como nos orientarmos em alto-mar com uma bússola, ou distinguir um objeto de sua imagem no espelho.

Kant pretende no artigo não apenas refutar a concepção leibniziana, mas provar a realidade do "espaço absoluto". Não é necessário, entretanto, que se veja seu argumento como uma adoção da concepção newtoniana do espaço (que rivalizara com a de Leibniz na primeira metade do século XVIII), embora o fato de falar em "espaço absoluto" e citar Euler (um defensor conhecido da concepção
\end{abstract}


newtoniana) como tendo procurado realizar a mesma prova, porém de modo $a$ posteriori, leve a crer que Kant viveu, de fato, um período newtoniano (cf. Roberto Torretti, Manuel Kant. Santiago, Universidade do Chile, 1967, § 12).

A prova de Kant procede metodologicamente segundo o disposto em sua Investigação sobre a clareza dos princípios da teologia natural e da moral, de 1764. Em filosofia, diz ele, contrariamente ao que sucede em matemática, devese partir não de definições, mas de fatos imediatamente evidentes. $O$ fato ao qual Kant apela na prova de 1768 é o de sermos capazes de distinguir direções espaciais. Sem levar em consideração que os corpos estão sempre voltados para uma certa direção, e que esta não pode ser apreendida pela mera descrição do modo como as partes do corpo estão situadas umas ao lado das outras, não seríamos capazes de distinguir duas contrapartidas incongruentes, como uma mão e sua imagem no espelho, por exemplo. A simples apresentação de contrapartidas incongruentes já é uma refutação de uma das teses de Leibniz, para o qual toda contrapartida seria congruente. Assim, ser similar (ter as partes dispostas entre si do mesmo modo) e igual (em tamanho) não implica ser congruente (poder ser enquadrado nos mesmos limites). Temos um exemplo aproximado disso no fato de que o pé direito de um sapato, embora seja em tudo similar e igual a seu par esquerdo, não serve a um pé esquerdo. A razão disso, diz Kant, é sua diversa orientação espacial. Se a orientação é uma característica interna (apreensível no objeto isolado) ou externa (só apreensível por comparação), é um ponto de difícil interpretação. Pois, embora Kant afirme que é interna (Ak. 382), diz também que só pode ser percebida com relação aos lados do corpo humano (Ak. 383). Ao que tudo indica, porém, Kant fez um uso ambíguo de "interno": ora "interno" referese a tudo o que é determinável pela comparação das partes do objeto isolado, ora refere-se também à orientabilidade (cf. P. Rusnock \& R. George, "A last shot at Kant and incongruent counterparts”. Em: Kant-Studien no 86, 1995).

Talvez se possa dizer que o ponto central do argumento, e que será retomado nos escritos posteriores, seja o de chamar a atenção para algo que não apreendemos de modo puramente descritivo, isto é, sem fazer referência a algo que não se esgota na descrição de um corpo isolado. Pois se algo está voltado para a direita, é com relação a um certo ponto de referência que está voltado nessa direção. Mas para mim, que estou situado no espaço, e que, portanto, não tenho acesso ao mundo desde um ponto de vista externo (ou, se se quiser, sub specie aeternitatis), não basta saber que o lado oposto ao da direita é o esquerdo, é preciso ainda saber apontar para onde fica a direita. Em 1768, saber apontar para uma direção indica que há algo (o "espaço absoluto") com relação ao qual as 
coisas estão orientadas, e que serve como marco de referência; de 1770 em diante, nós somos o marco de referência: para saber apontar numa direção é preciso uma intuição. Donde se vê a conexão com o desenvolvimento posterior de sua filosofia.

Assim, leitura do artigo pode ser interessante de um ponto de vista histórico, na medida em que mostra como a descoberta das contrapartidas incongruentes permitiu a Kant afastar-se das concepções leibnizianas, abrindo caminho para a compreensão da sensibilidade como uma fonte própria de conhecimento. Mas pode também ser interessante por mostrar a dificuldade em que incorre qualquer tentativa de dar conta das caraterísticas espaciais de um objeto em termos puramente descritivos, ou conceituais. Vale dizer, temos aí em germe um argumento, muito discutido em nosso século, em favor da não redutibilidade de dêiticos a predicados.

\section{Sobre a Tradução}

A tradução foi feita por Rogério Passos Severo (mestrando em filosofia UFRGS) e revisada pelo Prof. Valério Rohden. Utilizou-se a edição de Weischedel, exceto em poucas passagens para as quais preferiu-se a edição da Academia. A paginação da Academia está indicada no corpo do texto. A tradução foi comparada com a de Roberto Torretti para o espanhol (Diálogos. VIII, 22, 1972) e com a de S. Zac para o francês (Paris, Vrin, 1970), das quais se aproveitaram algumas soluções.

Preferiu-se traduzir Gegend por direção, e não por região, como é mais comum, por julgarmos que o texto fica desse modo mais inteligível. Os cinco primeiros parágrafos procuram mostrar que se a teoria leibniziana fosse verdadeira, não apenas seríamos incapazes de distinguir duas contrapartidas incongruentes, como tampouco poderíamos fazer coisas como usar uma bússola, ou saber como orientar uma folha escrita de modo a poder lê-la. O interesse que pode ter a discussão desses exemplos todos, que ocupa mais da metade do artigo, fica difícil de ser apreendido se entendermos Gegend como região, e não como direção. Além disso, certas frases ficam sem sentido, como, por exemplo, esta: "Mesmo nossos juízos sobre os pontos cardeais [Weltgegenden] são subordinados ao conceito que temos de direções [Gegenden] em geral, na medida em que são determinadas com relação aos lados do nosso corpo.” Ora, não são regiões que determinamos com relação aos lados do nosso corpo, e sim direções. Estar à minha direita não é uma região, pois minha direita varia conforme minha orientação e o lugar onde estou.

Este uso de Gegend, ademais, é possível em alemão (ver, por exemplo, Grimm, Deutsches Wörterbuch. Leipzig, Hirzel, 1897, vol. 4, tomo 1, parte 2, 
p. 2230) e era conhecido do próprio Kant. No §81 do apêndice Sobre a Navegação da Physische Geographie, por exemplo, diz "[Um navegador] deve saber para qual direção [Gegend] deve velejar (...) de modo a chegar a um lugar desejado." Ver também Versuch den Begriff der negativen Größen ...(Ak. 171), onde Gegend é empregado como sinônimo de Richtung.

/377/ Der berühmte Leibniz besaß viel wirkliche Einsichten, wodurch er die Wissenschaften bereicherte, aber noch viel größere Entwürfe zu solchen, deren Ausführung die Welt von ihm vergebens erwartet hat. Ob die Ursache darin zu setzen, daß ihm seine Versuche noch zu unvollendet schienen, eine Bedenklichkeit, welche verdienstvollen Männern eigen ist und die der Gelehrsamkeit jederzeit viel schätzbare Fragmente entzogen hat, oder ob es ihm gegangen ist, wie Boerhaave von großen Chemisten vermutet, daß sie öfters Kunststïcke vorgaben, als wenn sie im Besitze derselben wären, da sie eigentlich nur in der Überredung und dem Zutrauen zu ihrer Geschicklichkeit standen, daß ihnen die Ausführung derselben nicht mißlingen könnte, wenn sie einmal dieselbe übernehmen wollten, das will ich hier nicht entscheiden. Zum wenigsten hat es den Anschein, daß eine gewisse mathematische Disziplin, welche er zum voraus Analysin situs betitelte und deren Verlust unter andern Buffon bei Erwägung der Zusammenfaltungen der Natur in den Keimen bedauert hat, wohl niemals etwas mehr als ein Gedankending gewesen sei.Ich weiß nicht genau, inwiefern der Gegenstand, den ich mir hier zur Betrachtung vorsetze,
/377/ O célebre Leibniz teve conhecimentos muito efetivos com os quais enriqueceu as ciências, mas tinha ainda projetos muito maiores, cuja execução o mundo esperou dele em vão. Não quero aqui decidir se a causa disto reside no fato de que, para ele, suas tentativas ainda parecessem demasiado incompletas - uma escrupulosidade própria de homens de mérito e que privou a erudição de todos os tempos de fragmentos muito valiosos -, ou se com ele ocorreu o que Boerhaave conjetura sobre os grandes químicos, que freqüentemente alegavam poder obter produtos como se estivessem na posse dos mesmos, quando, na verdade, estavam apenas persuadidos e confiantes em sua habilidade técnica para produzi-los, e cuja execução não poderia falhar, caso quisessem empreendê-las. Pelo menos, parece que uma certa disciplina matemática que ele antecipadamente intitulou de analysis situs, e cuja perda Buffon, entre outros, lamentou ao considerar as pregas naturais nos embriões, nunca foi nada além de uma quimera. Não sei ao certo em que medida o objeto que aqui me proponho a considerar tem parentesco com o que o grande homem mencionado tinha em mente; a julgar apenas pelo significado das palavras, procuro aqui filosoficamente o primeiro fundamento da 
demjenigen verwandt sei, den der gedachte große Mann im Sinne hatte; allein nach der Wortbedeutung zu urteilen, suche ich hier philosophisch den ersten Grund der Möglichkeit desjenigen, wovon er die Größen mathematisch zu bestimmen vorhabens war. Denn die Lagen der Teile des Raums in Beziehung aufeinander setzen die Gegend voraus, nach welcher sie in solchem Verhältnis geordnet sind, und im abgezogensten Verstande besteht die Gegend nicht in der Beziehung eines Dinges im Raume auf das andere, welches eigentlich der Begriff der Lage ist, sondern in dem Verhältnisse des Systems dieser Lagen zu dem absoluten Weltraume. Bei allem Ausgedehnten ist die Lage seiner Teile gegen einander aus ihm selbst hinreichend zu erkennen, die Gegend aber, wohin diese Ordnung der Teile gerichtet ist, beziehet sich auf den Raum außer demselben und zwar /378/ nicht auf dessen Örter, weil dieses nichts anders sein würde, als die Lage ebenderselben Teile in einem äußeren Verhältnis, sondern auf den allgemeinen Raum als eine Einheit, wovon jede Ausdehnung wie ein Teil angesehen werden muß. Es ist kein Wunder, wenn der Leser diese Begriffe noch sehr unverständlich findet, die sich auch allererst im Fortgange aufklären sollen, ich setze daher nichts weiter hinzu, als daß mein Zweck in dieser Abhandlung sei, zu versuchen, ob nicht in den anschauenden Urteilen der Ausdehnung, dergleichen die Meßkunst enthält, ein evidenter Beweis zu finden sei, daß der possibilidade daquilo cujas grandezas ele tencionara determinar matematicamente. Pois as posições das partes do espaço nas suas relações recíprocas pressupõem a direção para a qual estão ordenadas em tal relação, e, num entendimento mais abstrato, a direção não consiste na relação de uma coisa no espaço com outra - o que é propriamente o conceito de posição -, mas na relação do sistema dessas posições com o espaço universal absoluto. Em tudo que seja extenso, a posição de suas partes umas em relação às outras pode ser conhecida suficientemente pela consideração da própria coisa extensa; mas a direção para a qual essa ordenação das partes está orientada refere-se ao espaço fora dela, e na verdade /378/ não aos seus lugares, pois isso nada mais seria do que a posição das partes mesmas em uma relação externa, mas sim ao espaço universal como uma unidade, do qual cada extensão tem de ser vista como uma parte. Não seria estranho se o leitor achasse ainda muito incompreensíveis esses conceitos que, antes de mais nada, também devem ser esclarecidos no que se segue. Por isso, não acrescento mais nada, senão que meu fim nesta dissertação seria o de investigar se nos juízos intuitivos da extensão, como os que a geometria contém, não se encontraria uma prova evidente de que o espaço absoluto, independentemente da existência de toda matéria e inclusive como primeiro fundamento da possibilidade de sua composição, tenha uma realidade própria. Todo mundo sabe como foram inúteis os esforços dos filósofos 
absolute Raum unabhängig von dem Dasein aller Materie und selbst als der erste Grund der Möglichkeit ihrer Zusammensetzung eine eigene Realität habe. Jedermann wei $\beta$, wie vergeblich die Bemühungen der Philosophen gewesen sind, diesen Punkt vermittelst der abgezogensten Urteile der Metaphysik einmal außer allen Streit zu setzen, und ich kenne keinen Versuch, dieses gleichsam a posteriori auszuführen, (nämlich vermittelst anderer unleugbaren Sätze, die selbst zwar außer dem Bezirke der Metaphysik liegen, aber doch durch deren Anwendung in concreto einen Probierstein von ihrer Richtichkeit abgeben können), als die Abhandlung des berühmten Eulers des Ältern in der Historie der K. Akad.d. W. zu Berl.vom Jahr 1748, die dennoch ihren Zweck nicht völlig erreicht, weil sie nur die Schwierigkeiten zeigt, den allgemeinsten Bewegungsgesetzen eine bestimmte Bedeutung zu geben, wenn man keinen andern Begriff des Raumes annimmt als denjenigen, der aus der Abstraktion von dem Verhältnis wirklicher Dinge entspringt, allein die nicht minderer Schwierigkeiten unberührt läßt, welche bei der Anwendung gedachter Gesetze übrig bleiben, wenn man sie nach dem Begriffe des absoluten Raumes in concreto vorstellen will. Der Beweis, den ich hier suche, soll nicht den Mechanikern, wie Herr Euler zur Absicht hatte, sondern selbst den Meßkuntlern einen überzeugenden Grund an die Hand geben, mit der ihnen gewöhnlichen Evidenz die no sentido de colocar de vez este ponto fora de qualquer disputa mediante os juízos mais abstratos da metafísica, e não conheço nenhuma tentativa de realizar isso como que a posteriori (a saber, mediante outras proposições irrefutáveis, que na verdade se encontram elas mesmas fora do domínio da metafísica, mas podem fornecer, por seu seu emprego in concreto, uma pedra de toque de sua correção), a não ser a dissertação do célebre Euler, o velho, [publicada] na História da Academia Real de Ciências de Berlim de 1748, que, contudo, não alcançou completamente seu fim, pois apenas mostra as dificuldades de se dar um significado determinado às leis mais gerais do movimento, se não se aceita nenhum outro conceito de espaço a não ser aquele que resulta da abstração da relação entre coisas existentes, deixando intactas, contudo, as não menores dificuldades que permanecem quando da aplicação das leis em questão, se se quer representá-las in concreto segundo o conceito de espaço absoluto. A prova que aqui procuro deve fornecer não aos mecânicos, como o Senhor Euler tinha em vista, mas aos próprios geômetras uma razão convincente para que possam afirmar, com sua evidência habitual, a realidade do seu espaço absoluto. Para isso, apresento as seguintes preliminares. 
Wirklichkeit ihres absoluten Raumes behaupten zu können. Ich mache dazu folgende Vorbereitung.

In dem körperlichen Raume lassen sich wegen seiner drei Abmessungen drei Flächen denken, die einander insgesamt rechtwincklicht schneiden. Da wir alles, was außer uns ist, durch die Sinnen nur insoferne kennen, als es in Beziehung auf uns selbst stehet, so ist kein Wunder, daß wir von der Verhältnis dieser Durchschnittsflächen zu unserem Körper den ersten Grund hernehmen, den Begriff der Gegenden im Raume zu /379/ erzeugen. Die Fläche, worauf die Länge unseres Körpers senkrecht stehet, heißt in Ansehung unser horizontal; und diese Horizontalfläch gibt Anlaß zu der Unterschiede der Gegenden, die wir durch oben und unten bezeichnen. Auf dieser Fläche können zween andere senkrecht stehen und sich zugleich rechwincklich durchkreuzen, sodaß die Länge des menschlichen Körpers in der Linie des Durchschnitts gedacht wird. Die eine dieser Vertikalflächen teilet den Körper in zwei äußerlich ähnliche Hälften und gibt den Grund des Unterschiedes der rechten und linken Seite $a b$, die andere, welche auf ihr perpendikular stehet, machet, daß wir den Begriff der vorderen und hinteren Seite haben können. Bei einem beschriebenen Blatte z. E. unterscheiden wir zuerst die obere von der unteren Seite der Schrift, wir bemerken den Unterschied der vorderen und hintern Seite, und dann sehen wir auf die Lage der Schriftzüge von der Linken
No espaço corpóreo, por causa de suas três dimensões, deixam-se pensar três planos, que se entrecortam todos em ângulos retos. Uma vez que conhecemos, mediante os sentidos, tudo o que está fora de nós somente na medida em que se encontre em relação conosco, não é de estranhar que para gerar o primeiro fundamento do conceito de direções no espaço, partamos da relação destes planos de interseção com nosso corpo. /379/ O plano perpendicular ao comprimento de nosso corpo chama-se, em relação a nós, horizontal; e esse plano horizontal dá ensejo à distinção das direções que designamos por acima e abaixo. Sobre este plano podem estar dois outros, perpendiculares e cruzando-se igualmente em ângulos retos, de modo que o comprimento do corpo humano é pensado na linha de interseção. Um destes planos verticais divide o corpo em duas metades exteriormente similares e dá o fundamento da distinção entre o lado direito e o esquerdo; o outro, que lhe é perpendicular, faz com que possamos ter o conceito de lado de frente e de trás. Em uma folha escrita, por exemplo, distinguimos primeiro o lado de cima do de baixo da escrita, observamos a distinção dos lados frente e verso, e então vemos a posição da letra da esquerda para a direita ou ao contrário. Aqui, a posição recíproca das partes ordenadas sobre a superfície é sempre a mesma e se constitui em uma figura inteiramente idêntica, podendo-se 
gegen die Rechte oder umgekehrt. Hier ist immer ebendieselbe Lage der Teile, die auf der Fläche geordnet sind, gegen einander und in allen Stücken einerlei Figur, man mag das Blatt drehen, wie man will, aber der Unterschied der Gegenden kommt bei dieser Vorstellung so sehr in Anschlag und ist mit dem Eindrucke, den der sichtbare Gegenstand macht, so genau verbunden, daß ebendieselbe Schrift, auf solche Weise gesehen, daß allen von der Rechten gegen die Linke gekehret wird, was vorher die entgegengesetzte Gegend hielt, unkenntlich wird.

Sogar sind unsere Urteile von den Weltgegenden dem Begriffe untergeordnet, den wir von Gegenden überhaupt haben, insoferne sie in Verhältnis auf die Seiten unseres Körpers bestimmt sind. Was wir sonsten am Himmel und auf der Erde unabhängig von diesem Grundbegriffe an Verhältnissen erkennen, das sind nur Lagen der Gegenstände unter einander. Wenn ich auch noch so gut die Ordnung der Abteilungen des Horizonts weiß, so kann ich doch die Gegenden darnach nur bestimmen, indem ich mir bewußt bin, nach welcher Hand diese Ordnung fortlaufe, und die allergenaueste Himmelskarte, wenn außer der Lage der Sterne untereinander nicht noch durch die Stellung des Abrisses gegen meine Hände die Gegend determiniert würde, so genau wie ich sie auch in Gedanken hätte, würde mich doch nicht in den Stand setzen, aus einer bekannten Gegend, z. E. Norden, zu wissen, auf welche Seite des Horizonts virar a folha como se quiser; mas a distinção das direções tem tanta importância nesta representação e está tão estreitamente ligada à impressão que o objeto visível produz, que a mesma escrita torna-se irreconhecível quando vista de tal modo que seja volvido da direita para a esquerda tudo o que antes tomava a direção contrária.

Mesmo nossos juízos sobre os pontos cardeais são subordinados ao conceito que temos de direções em geral, na medida em que estão determinados com relação aos lados do nosso corpo. As demais relações que conhecemos no céu e na terra independentemente desses conceitos fundamentais são apenas posições dos objetos entre si. Por melhor que eu também conheça a ordem dos quadrantes do horizonte, só poderei determinar as direções por meio disso se estiver consciente da mão a partir da qual essa ordem segue; e o planisfério mais preciso, por mais precisamente também que o tivesse em meu pensamento, não me colocaria em posição de saber, a partir de uma direção conhecida, do norte, por exemplo, de que lado do horizonte teria de procurar o nascer do sol, se a direção não fosse determinada não apenas pela posição das estrelas entre si, mas também pela situação do diagrama em relação às minhas mãos. O mesmo ocorre com o conhecimento 
ich den Sonnenaufgang zu suchen hätte. Ebenso ist es mit der geographischen, ja mit unserer gemeinsten Kenntnis der Lage der Örter bewandt, die uns zu nichts hilft, wenn wir die so geordnete Dinge und das ganze System der wech 1380/ selseitigen Lagen nicht durch die Beziehung auf die Seiten unseres Körpers nach den Gegenden stellen können. Sogar bestehet ein sehr namhaftes Kennzeichen der Naturerzeugungen, welches gelegentlich selbst zum Unterschiede der Arten Anlaß geben kann, in der bestimmten Gegend, wornach die Ordnung ihrer Teile gekehrt ist und wodurch zwei Geschöpfe können unterschieden werden, obgleich sie sowohl in Ansehung der Größe als auch der Proportion und selbst der Lage der Teile untereinander völlig übereinkommen möchten. Die Haare auf dem Wirbel aller Menschen sind von der Linken gegen die Rechte gewandt. Aller Hopfen windet sich von der Linken gegen die Rechte um seine Stange; die Bohnen aber nehmen eine entgegengesetzte Wendung. Fast alle Schnecken, nur etwa drei Gattungen ausgenommen, haben ihre Drehung, wenn man von oben herab, d. i. von der Spitze zur Mündung gehet, von der Linken gegen die Rechte. Diese bestimmte Eigenschaft wohnet ebenderselben Gattung von Geschöpfen unveränderlich bei ohne einiges Verhältnis auf die Halbkugel, woselbst sie sich befinden, und auf die Richtung der täglichen Sonnenund Mondsbewegung, die uns von der Linken gegen die Rechte, unsern geográfico e também com o nosso conhecimento mais comum da posição dos lugares, que em nada nos ajuda, se não podemos colocar as coisas desse modo ordenadas e o sistema todo das /380/ posições recíprocas em uma relação com os lados de nosso corpo de acordo com as direções. Existe até mesmo uma característica muito notável nos seres vivos, que ocasionalmente pode até dar ensejo a diferenças de espécies, consistente na direção determinada para a qual a ordem de suas partes está voltada e pela qual podem-se diferenciar duas criaturas, ainda que coincidam inteiramente tanto no que diz respeito ao tamanho quanto também na proporção e até mesmo na posição recíproca das partes. Os cabelos no alto da cabeça de todos os homens são voltados da esquerda para a direita. Todo lúpulo enroscase da esquerda para a direita em sua rama; já o feijão volta-se no sentido contrário. Quase todos os caracóis, exceto apenas umas três espécies, têm sua torção da esquerda para a direita quando se olha de cima, isto é, da cúspide à boca. Essa qualidade determinada reside invariavelmente nestas mesmas espécies de criaturas, sem relação alguma com o hemisfério onde as mesmas se encontram, nem com a orientação da rotação diária do sol e da lua, que para nós vai da esquerda para a direita, mas para nossos antípodas vai [no sentido] contrário; pois nos produtos naturais mencionados, a causa da circunvolução repousa na própria semente. Por outro lado, onde uma certa rotação pode ser atribuída ao curso destes corpos celes- 
Antipoden aber diesem entgegen läuft, weil bei den angeführten Naturprodukten die Ursache der Windung in den Samen selbst liegt; dahingegen wo eine gewisse Drehung dem Laufe dieser Himmelskörper zugeschrieben werden kann, wie Mariotte ein solches Gesetz an den Winden will beobachtet haben, die vom neuen zum vollen Lichte gerne von der Linken zur Rechten den ganzen Kompaß durchlaufen, da muß diese Kreisbewegung auf der anderen Halbkugel nach der andern Hand herumgehen, wie es auch wirklich Don Ulloa durch seine Beobachtungen auf dem südlichen Meere bestätigt zu finden meinet.

Da das verschiedene Gefühl der rechten und linken Seite zum Urteil der Gegenden von so großer Notwendigkeit ist, so hat die Natur es zugleich an die mechanische Einrichtung des menschlichen Körpers geknüpft, vermittelst deren die eine, nämlich die rechte Seite, einen ungezweifelten Vorzug der Gewandtheit und vielleicht auch der Stärke vor der linken hat. Daher alle Völker der Erde rechtsch sind, (wenn man einzelne Ausnahmen beiseite setzt, welche, so wie die des Schielens, die Allgemeinheit der Regel nach der natürlichen Ordnung nicht umstoßen können). Man bewegt seinen Körper leichter von der Rechten gegen die Linke als diesem entgegen, wenn man aufs Pferd steigt oder über einen Graben schreitet. Man schreibt allerwärts mit der rechten Hand, und mit ihr /381/ tut man alles, wozu Geschicke und Stärke erfordert wird. So wie aber tes - como a lei que Mariotte pretende ter observado em relação aos ventos, que percorreriam de boa mente toda a bússola, do alvorecer ao meio-dia, da esquerda para a direita - aí este movimento circular tem de proceder no sentido inverso no outro hemisfério, como também Don Ulloa pensa ter efetivamente confirmado mediante suas observações sobre os mares do sul.

Visto que o sentimento diverso dos lados direito e esquerdo é de tão grande necessidade para o juízo de direções, a natureza conectou-o simultaneamente com o arranjo mecânico do corpo humano, por meio do qual um dos lados, a saber, o direito, tem uma vantagem indubitável em agilidade e talvez também em força sobre o esquerdo. Eis por que todos os povos da Terra são destros (se se desconsidera exceções isoladas, as quais, como a do estrabismo, não podem revogar a universalidade da regra de acordo com a ordem natural). É mais fácil mover o corpo da direita para a esquerda do que ao contrário quando se monta o cavalo ou se atravessa um fosso. Escreve-se, por toda a parte, com a mão direita, e com ela /381/ se faz tudo aquilo para o que é requerido habilidade e força. Porém, assim como o lado direito parece ter vantagem sobre o esquerdo no que diz respeito à mobi- 
die rechte Seite vor der linken den Vorteil der Bewegkraft zu haben scheint, so hat die linke ihn vor der rechten in Ansehung der Empfindsamkeit, wenn man einigen Naturforschern glauben darf, z. E. dem Borelli und Bonnet, deren der erstere von dem linken Auge, der andere auch vom linken Ohre behauptet, da $\beta$ der Sinn in ihnen stärker sei als der an den gleichnamigen Werkzeugen der rechten Seite. Und so sind die beiden Seiten des menschlichen Körpers ungeachtet ihrer großen äußeren Ähnlichkeit durch eine klare Empfindung gnugsam unterschieden, wenn man gleich die verschiedene Lage der inwendigen Teile und das merkliche Klopfen des Herzens beiseite setzt, indem dieser Muskel bei seinem jedesmaligen Zusammenziehen mit seiner Spitze in schiefer Bewegung an die linke Seite der Brust anstößt.

Wir wollen also dartun, daß der vollständige Bestimmungsgrund einer körperlichen Gestalt nicht lediglich auf demVerhältnis und Lage seiner Teile gegen einander beruhe, sondern noch überdem auf einer Beziehung gegen den allgemeinen absoluten Raum, so wie ihn sich die Meßkünstler denken, doch so, daß dieses Verhältnis nicht unmittelbar kann wahrgenommen werden, aber wohl diejenige Unterschiede der Körper, die einzig und allein auf diesem Grunde beruhen. Wenn zwei Figuren, auf einer Ebene gezeichnet, einander gleich und ähnlich sind, so decken sie einander. Allein mit der körperlichen Ausdehnung oder auch den Linien und Flächen, die nicht in einer Ebene lidade, o esquerdo a tem sobre o direito no tocante à sensibilidade, se nos for permitido acreditar em alguns naturalistas, como por exemplo Borelli e Bonnet, o primeiro dos quais afirma a respeito do olho esquerdo, o segundo também do ouvido esquerdo, que neles o sentido é mais forte do que nos instrumentos homônimos do lado direito. E assim, os dois lados do corpo humano, apesar de sua grande similaridade exterior, são suficientemente distinguidos por uma sensação clara, mesmo que se desconsidere igualmente as posições diferentes das partes internas e a batida perceptível do coração, quando este músculo, a cada contração, bate do lado esquerdo do peito com sua extremidade em movimento oblíquo.

Queremos, portanto, provar que o fundamento de determinação completo de uma forma corpórea não depende meramente da relação e da posição de suas partes umas com as outras, mas, além disso, de uma relação com o espaço absoluto universal, como o que os geômetras pensam, ainda que, entretanto, não se possa perceber imediatamente esta relação, mas sim, contudo, aquelas diferenças entre corpos que dependem unica e exclusivamente deste fundamento. Se duas figuras, desenhadas sobre um plano, são iguais e similares entre si, então elas recobrem-se mutuamente. Todavia, com a extensão corpórea, e também com as linhas e superfícies que não se encontram em um pla- 
liegen, ist es oft ganz anders bewandt. Sie können völlig gleich und ähnlich, jedoch an sich selbst so verschieden sein, daß die Grenzen der einen nicht zugleich die Grenzen der andern sein können. Ein Schraubengewinde, welches um seine Spille von der Linken gegen die Rechte geführet ist, wird in eine solche Mutter niemals passen, deren Gänge von der Rechten gegen die Linke laufen, obgleich die Dicke der Spindel und die Zahl der Schraubengänge in gleicher Höhe einstimmig wären. Ein sphärischer Triangel kann einem andern völlig gleich und ähnlich sein, ohne ihn doch zu decken. Doch das gemeinste und kläreste Beispiel haben wir an den Gliedmaßen des menschlichen Körpers, welche gegen die Vertikalfläche desselben symmetrisch geordnet sind. Die rechte Hand ist der linken ähnlich und gleich, und wenn man blo $\beta$ auf eine derselben allein sieht, auf die Proportion und Lage der Teile unter einander und auf die Größe des Ganzen, so ти $\beta$ eine vollständige Beschreibung der einen in allen Stücken auch von der andern gelten.

/382/ Ich nenne einen Körper, der einem ander völlig gleich und ähnlich ist, ob er gleich nicht in ebendenselben Grenzen kann beschlossen werden, sein inkongruentes Gegenstück. Um nun dessen Möglichkeit zu zeigen, so nehme man einen Körper an, der nicht aus zwei Hälften bestehet, die symmetrisch gegen eine einzige Durchschnittsfläche geordnet sind, sondern etwa eine Menschenhand. Man fälle aus allen Punkten ihrer Oberfläche auf eine no, as coisas passam-se freqüentemente de modo bem diverso. Elas podem ser completamente iguais e similares e, contudo, ser em si mesmas tão diferentes que os limites de uma não podem ser simultaneamente os limites da outra. Um parafuso cuja rosca procede da esquerda para a direita nunca servirá a uma porca cuja rosca vai da direita para a esquerda, mesmo que sua espessura e o número de voltas do parafuso fossem iguais na mesma altura. Um triângulo esférico pode ser completamente igual e similar a outro, sem entretanto recobrilo. Temos, porém, o exemplo mais comum e claro [disso] nos membros do corpo humano, que são ordenados simetricamente no plano vertical do mesmo. A mão direita é similar e igual à esquerda, e se olharmos apenas para uma delas isoladamente, para a proporção e posição recíproca das partes e para a grandeza do todo, uma descrição completa de uma também tem de valer inteiramente para a outra.

1382/ Designo um corpo completamente igual e similar a outro, e que mesmo assim não pode ser incluído nos mesmos limites, de sua contrapartida incongruente. Para mostrar então sua possibilidade, tome-se um corpo que não seja composto de duas metades ordenadas simetricamente de acordo com um plano de interseção único, como uma mão humana. Baixem-se de todos os pontos de sua superfície linhas perpendiculares a um quadro colocado em fren- 
gegen ihr übergestellete Tafel Perpendikellinien und verlängere sie ebenso weit hinter derselben, als diese Punkte vor ihr liegen, so machen die Endpunkte der so verlängerten Linien, wenn sie verbunden werden, die Fläche einer körperlichen Gestalt aus, die das inkongruente Gegenstück der vorigen $i$ ist, $d$. $i$. wenn die gegebene Hand eine rechte ist, so ist deren Gegenstück eine linke. Die Abbildung eines Objekts im Spiegel beruhet auf ebendenselben Gründen. Denn es erscheinet jederzeit ebensoweit hinter demselben, als es vor seiner Fläche stehet, und daher ist das Bild einer rechten Hand in demselben jederzeit eine linke. Bestehet das Objekt selber aus zwei inkongruenten Gegenstücken, wie der menschliche Körper, wenn man ihn vermittelst eines Vertikaldurchschnitts von vorne nach hinten teilet, so ist sein Bild ihm kongruent, welches man leicht erkennet, wenn man es in Gedanken eine halbe Drehung machen läßt; denn das Gegenstück vom Gegenstücke eines Objekts ist diesem notwendig kongruent.

So viel mag gnug sein, um die Möglichkeit völlig ähnlicher und gleicher und doch inkongruenter Räume zu verstehen. Wir gehen jetzt zur philosophischen Anwendung dieser Begriffe. Es ist schon aus dem gemeinen Beispiele beider Hände offenbar, daß die Figur eines Körpers der Figur eines andern völlig ähnlich und die Größe der Ausdehnung ganz gleich sein könne, so daß dennoch ein innerer Unterschied übrig bleibt, nämlich der, daß die Oberfläche, die den einen beschließt, te, e prolonguem-se as linhas do mesmo modo para trás numa distância equivalente à que há entre os pontos e o quadro; deste modo, os pontos finais da linha assim prolongada constituem (se forem ligados) a superfície de uma forma corpórea que é a contrapartida incongruente da precedente; isto é, se a mão dada é direita, então sua contrapartida é uma [mão] esquerda. A imagem de um objeto no espelho baseia-se nos mesmos fundamentos. Pois o objeto aparece sempre atrás do espelho na mesma distância em que se encontra diante dele, e por isso a imagem de uma mão direita nele sempre ser a de uma [mão] esquerda. Se o próprio objeto é composto de duas contrapartidas incongruentes, como o corpo humano, quando se o divide por meio de um corte vertical de frente para trás, então sua imagem lhe é congruente, o que se reconhece facilmente, quando em pensamento o deixamos fazer uma meia volta; pois a contrapartida da contrapartida de um objeto lhe é necessariamente congruente.

Isso deve ser suficiente para compreender a possibilidade de espaços completamente similares e iguais, e mesmo assim incongruentes. Passamos agora ao emprego filosófico desses conceitos. Já é evidente nos exemplos comuns das duas mãos que a figura de um corpo pode ser completamente similar à figura de outro, e que a grandeza de sua extensão pode ser totalmente igual à de outro, de modo tal que reste, contudo, uma diferença interna, a saber, que a superfície que inclui um não pode en- 
den andern unmöglich einschließen könne. Weil diese Oberfläche den körperlichen Raum des einen begrenzt, die dem andern nicht zur Grenze dienen kann, man mag ihn drehen und wenden, wie man will, so muß diese Verschiedenheit eine solche sein, die auf einem inneren Grunde beruhet. Dieser innere Grund der Verschiedenheit aber kann nicht auf die unterschiedene Art der Verbindung der Teile des Körpers untereinander ankommen; denn wie man aus dem angeführten Beispiele siehet, so kann in Ansehung dessen alles völlig einerlei sein. Gleichwohl, wenn man sich vorstellet, das erste Schöpfungsstück solle eine Menschenhand sein, so ist es notwendig ent /383/ weder eine Rechte oder eine Linke, und um die eine hervorzubringen, war eine andere Handlung der schaffenden Ursache nötig, als die, wodurch ihr Gegenstück gemacht werden konnte.

Nimmt man nun den Begriff vieler neueren Philosophen, vornehmlich der deutschen an, daß der Raum nur in dem äußeren Verhältnisse der nebeneinander befindlichen Teile der Materie bestehe, so würde aller wirkliche Raum in dem angeführten Falle nur derjenige sein, den diese Hand einnimmt. Weil aber gar kein Unterschied in dem Verhältnisse der Teile derselben unter sich stattfindet, sie mag eine Rechte oder Linke sein, so würde diese Hand in Ansehung einer solchen Eigenschaft gänzlich unbestimmt sein, d.i. sie würde auf jede Seite des menschlichen Körpers passen, welches unmöglich ist . cerrar o outro. Visto que esta superfície, que limita o espaço corpóreo de um, não pode servir de limite para o outro, podendo-se rodá-la e virá-la como se quiser, então esta diferenciação tem de se basear em um fundamento interno. Porém, este fundamento interno da diferenciação não pode depender do modo distinto de ligação das partes do corpo umas com as outras; pois, como se vê pelo exemplo mencionado, no tocante a isto tudo pode ser completamente idêntico. Não obstante, se imaginamos o primeiro elemento da criação como sendo uma mão humana, então necessariamente teria de ser ou /383/ direita ou esquerda, e para produzi-la seria preciso um ato diferente da causa criadora do que aquele pelo qual sua contrapartida pôde ser criada.

Ora, se aceitarmos a concepção de muitos filósofos recentes, principalmente alemães, segundo a qual o espaço consistiria apenas nas relações externas das partes da matéria situadas umas ao lado das outras, então no caso mencionado todo espaço efetivo seria apenas aquele que esta mão ocupa. Visto, porém, que não há nenhuma diferença na relação das partes da mesma entre si, quer ela seja direita ou esquerda, então esta mão seria, no que se refere a esta qualidade, totalmente indeterminada, isto é, ela serviria em ambos os lados do corpo humano, o que é impossível. 
Es ist hieraus klar, daß nicht die Bestimmungen des Raumes Folgen von den Lagen der Teile der Materie gegeneinander, sondern diese Folgen von jenen sind, und da $\beta$ also in der Beschaffenheit der Körper Unterschiede angetroffen werden können und zwar wahre Unterschiede, die sich lediglich auf den absoluten und ursprünglichen Raum beziehen, weil nur durch ihn das Verhältnis körperlicher Dinge möglich ist, und daß, weil der absolute Raum kein Gegenstand einer äußeren Empfindung, sondern ein Grundbegriff ist, der alle dieselbe zuerst möglich macht, wir dasjenige, was in der Gestalt eines Körpers lediglich die Beziehung auf den reinen Raum angehet, nur durch die Gegenhaltung mit andern Körpern vernehmen können.

Ein nachsinnender Leser wird daher den Begriff des Raumes, so wie ihn der Meßkü̈nstler denkt und auch scharfsinnige Philosophen ihn in den Lehrbegriff der Naturwissenschaft aufgenommen haben, nicht für ein bloßes Gedankending ansehen, obgleich es nicht an Schwierigkeiten fehlt, die diesen Begriff umgeben, wenn man seine Realität, welche dem innern Sinne anschauend gnug ist, durch Vernunftideen fassen will. Aber diese Beschwerlichkeit zeiget sich allerwärts, wenn man über die ersten Data unserer Erkenntnis noch philosophieren will, aber sie ist niemals so entscheidend als diejenige, welche sich hervortut, wenn die Folgen eines angenommenen Begriffs der augenscheinlichsten Erfahrung widersprechen.
Disso fica claro que não são as determinações do espaço conseqüências das posições recíprocas das partes da matéria, mas estas é que são conseqüências daquelas, e que também na natureza dos corpos podem ser encontradas diferenças, e de fato verdadeiras diferenças, que dizem respeito unicamente ao espaço absoluto e originário, pois apenas por meio dele a relação com as coisas corpóreas é possível; e que, como o espaço absoluto não é um objeto da sensação externa, mas um conceito fundamental que os torna todos em primeiro lugar possíveis, nós podemos perceber aquilo que na forma de um corpo diz respeito unicamente à relação com o espaço puro somente pela comparação com outros corpos.

Por isso, um leitor reflexivo considerará o conceito de espaço - tal como o geômetra o pensa, e também filósofos sagazes adotaram-no no sistema da ciência natural - não como uma simples quimera, ainda que não faltem dificuldades envolvendo este conceito, se se quer apreender sua realidade, que é suficientemente intuída pelo sentido interno, por meio de idéias da razão. Mas esta incômodo mostra-se por toda parte, se se quer ainda filosofar sobre os primeiros dados de nosso conhecimento, mas ela não é jamais tão decisiva como aquela que se apresenta quando as conseqüências de um conceito adotado contradizem a experiência mais evidente. 